\title{
Research Hotspots and Tendencies of Family Firms in China
}

\author{
Jiaqi Guo*, Changhong Li, Wenting Jiao, Zhan Wang \\ School of Economics and Management, Shanxi University, Taiyuan, China \\ Email: ^gjq602@163.com, lch7320@sxu.edu.cn, jiao@sxu.edu.cn, zhanwang@sxu.edu.cn
}

How to cite this paper: Guo, J.Q., Li, C.H., Jiao, W.T. and Wang, Z. (2019) Research Hotspots and Tendencies of Family Firms in China. Theoretical Economics Letters, 9, 1053-1069.

https://doi.org/10.4236/tel.2019.94068

Received: February 26, 2019

Accepted: April 21, 2019

Published: April 24, 2019

Copyright $\odot 2019$ by author(s) and Scientific Research Publishing Inc. This work is licensed under the Creative Commons Attribution International License (CC BY 4.0).

http://creativecommons.org/licenses/by/4.0/

(c) (i) Open Access

\begin{abstract}
Family firm is a unique type of organization that has existed for a long time; however, it has only been researched recently as a mainstream subject in organization and management studies. Due to their significant heterogeneity, relevant studies in China and other countries present both common features, and diverse characteristics, which embedded in different contexts. To better understand how the family firm's theory can enhance the development of family firm studies in China, we analyze and compare the evolution of family firm's studies in China and other countries of the world. The paper built on the databases, Web of Science (WoS) and Chinese Social Sciences Citation Index (CSSCI), and use CiteSpace V, which is software for visualizing knowledge domains. The result shows that: 1) there are many studies on the governance, succession and performance of family firms in both China and other countries; 2) in literature of WoS, the literature had transformed from governance of company to a deep understanding of the influences of family characteristics on business strategy and entrepreneurship; 3) most studies of the Chinese family firm are about firm governance. Nevertheless, the definition and studies on family firms fail to connect with the Chinese culture and understanding of "family". Additionally, the aspects, such as sustainable development, ecological efficiency and international competition of family firms, need further exploration.
\end{abstract}

\section{Keywords}

Family Firms, CiteSpace V, Bibliometrics, WoS, CSSCI, China

\section{Introduction}

Family firms are the earliest form of organizations in the world and exert significant influences on social and economic development. According to a survey 
conducted by Family Business Review, an authoritative academic journal of family firms, $70 \%$ to $90 \%$ of the global gross domestic product (GDP) was created by family firms. However, few scholars had conducted studies on family organizations before the launch of Family Business Review in 1988, which made the rationality and necessity of studying family firms gain recognition by academia. Since then, the study of family firms has gradually become a relatively independent research field.

Many developed countries hold a negative view of Chinese family firms, associated them with information opacity and arbitrary entrepreneurs. However, Chinese family firms have adapted well to the institutional environment in the economic transition period and have made substantial contributions to the development of the national economy, relying on their stimulation of entrepreneurship and effective control over costs.

As shown in the seventh survey on modern family firms launched by Forbes China in 2016, there were 912 family firms among the 1621 private enterprises listed in the A-share market, accounting for $56 \%$. It is evident that family firms play a role in the Chinese economic structure. While long permeated by the unique family culture in China, family firms do not only play a role in the economy but also are an important medium for the inheritance of traditional culture. Therefore, a systematic summary of studies on Chinese family firms is of great significance to their development and the enrichment of studies on them in the world.

As the family firm has become a relatively independent academic field, studies of family firms show explosive growth in recent years. Big data has received wide attention from academia, the economic communities and governments [1]. Currently, popular research topics of family firms are mainly analyzed in the form of literature reviews. According to their own research orientations, scholars summarize studies from different perspectives. Such reviews are too objective, which comprehensively reflect on the popular topics, approaches, and development trends of research in this field. Chinese family firms have many characteristics and shortcomings distinguished them in developed capital markets, influenced by Chinese politics and a culture of thousands of years old. Additionally, Chinese family firms are still in their infancy as compared with firms in other countries, thus they could gain valuable insights from relevant research on family firms in other countries.

So we used software programs such as CiteSpace and Excel to make a quantitative analysis of literature on family firms in China and other countries. This study used the WoS and CSSCI databases to make an objective and intuitive comparison through scientific measurement, thus providing inspiration and guidance for later studies on Chinese family firms.

Our study contributes to the literature in two ways. First, we have conducted a systematic literature review on study of family firms in China using the way of bibliometrics and visualization. Bibliometrics is the cross-disciplinary science of quantitative analysis of all knowledge carriers by mathematical and statistical

${ }^{1}$ Since 2009, Forbes China has conducted surveys of listed family businesses in China every year. 
methods [2]. It is a commonly used method to identify the development of a certain field [3]. Second, we did a comparative analysis of reviews on family firms in China and other countries. For the representativeness and authority of big data, we selected Web of Science (WoS) and Chinese Social Sciences Citation Index (CSSCI) databases as our source.

The rest of this paper proceeds as follows. Section 2 describes the data collection and bibliometric analysis. Section 3 is temporal distribution. Section 4 reviews related literature of study of family firms based on co-occurrence of keywords and burst terms. Section 5 sets forth our conclusion.

\section{Data Collection and Bibliometric Analysis}

\subsection{Data Collection}

To enhance future research and draw insights on family firms in China, the articles were mainly retrieved from the core collections of WoS and the CSSCI. WoS covers bibliographic databases of Science Citation Index Expanded (SCIE) and the Social Science Citation Index (SSCI), and CSSCI covers databases of core journals and the Chinese Social Sciences Citation Index. Web of Science, the largest source of comprehensive academic information, covering the most numerous disciplines, collects over 8700 core academic journals most influential in their respective fields. Rigorous evaluations maintained by the database indicate that the indexed literature is of considerably high academic value. CSSCI, a major national-level program sponsored by the Ministry of Education, adopts a database developed by the Chinese Social Sciences Research Evaluation Center of Nanjing University, which can be used to retrieve indexed academic papers and citations of literature in Chinese social sciences. It is considered to be a characteristic program in the field of research evaluation of Chinese humanities and social sciences. So when we compared family businesses between China and other countries, we chose the WoS and CSSCI databases to ensure the academic value of the target literature.

The search terms for WoS were "family firm" and "family business," and the span of publication time was between 1999 and 2017. Then we deleted articles on Chinese family businesses based on the keywords "China" and "Chinese," and we got 1751 articles from other countries besides China. Considering the extensive and profound Chinese language, the search terms for CSSCI were "family business/firm," "family control," and "family involvement," and we got 883 articles between 2001 and $2015^{2}$. CiteSpace collects scientific text data, which contain all literature information except the main body. Bibliographic data include literature type, author, journal, key words, abstract, institution, country, and reference literature. As the data of CSSCI were exported without keywords, the authors manually added keywords to the bibliographic data of every article after exporting 883 papers. We analyzed abstracts of articles in the process of keyword supplementation to ensure the selected literature is valid in terms of ${ }^{2}$ The span of publication for CSSCI is $1998-2015$. The literature about family firms/businesses in CSSCI appeared from 2001, so we got the relevant articles between 2011 and 2015. 
studying family firms in China.

\subsection{Bibliometric Analysis}

Bibliometric analysis combines visualization, graphics, and scientific metrics, and it takes evolving scientific knowledge as the object of study [4]. It is applied to quantitatively evaluate the quality of research outputs, research tendencies, and implicit knowledge structures [5] for comprehensive and in-depth understanding of extant literature [6] [7].

We selected the latest version, CiteSpace V, as the analysis tool. CiteSpace is a Java application for analyzing and visualizing co-citation networks [6], including co-citation references, co-authors, and co-occurring keywords.

Through bibliometric analysis, scholars can analyze co-occurrences of keywords and detect burst terms and time zones to map research trends of family firms/businesses. First, co-occurrences of keywords means that two different keywords appear in the same article. As keywords present the central contents of studies, high frequencies of co-occurring keywords can be used to reflect hot research topics. These research topics can be further clustered into higher-level abstractions [7]. Second, different from the frequency of co-occurrences of keywords, we also examined the changes in frequency of keywords over time. Keywords with rapidly increasing frequency in a certain period of time are referred to as burst terms. Burst terms point to the density of occurrences of keywords in a certain period of time, reflecting hot research topics in a temporal dimension [8]. Time zone detects words of high frequency from a large number of keywords, then determines the frontier domains and the developing trends through the time distribution of the words of high frequency. Therefore, by mapping the changes of burst terms and time zones over time, scholars can trace the tendencies of the research field.

\section{Temporal Distribution}

Figure 1 show that temporal distribution of literature from the Chinese Social Sciences Citation Index (CSSCI) and Web of Science (WoS) databases. The WoS database in this paper covers data from 1990 to 2017, and statistical data from CSSCI is from 2001 to 2015. Statistics of the WoS database are within the timespan from 1986 to 2017, but literature on family firms did not appear until 1990, and Family Business Review started publication in 1988, after which research on family firms by scholars in China and other countries gradually became a relatively independent research field. Figure 1 shows that research on family firms in WoS developed quickly since 2005. The articles on family firms in CSSCI lagged behind articles in WoS to a certain extent, in terms of time distribution and quantity. There were few papers on family firms in China before 1998, and after that the number began to increase sharply ${ }^{3}$. The number of articles reached ${ }^{3}$ The conclusion was proved further by a query on CNKI. In the journal database of CNKI, 2451 papers published between 1988 and 2017 were found with "family firms" as a keyword, of which the earliest was published in 1993, and only 18 papers were published between 1993 and 1997. 


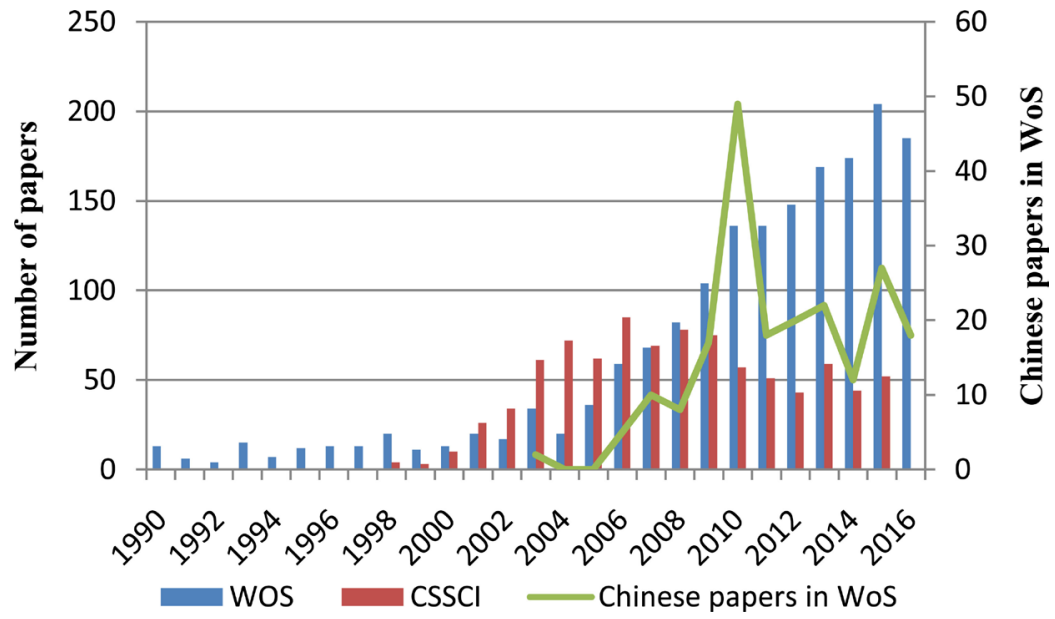

Figure 1. Temporal distribution of literature from the Chinese Social Sciences Citation Index (CSSCI) and Web of Science (WoS) databases.

an all-time high in 2006, when the number of papers published was 21 times more than in 1998, which showed a decreasing tendency.

As the WoS database contains articles by Chinese scholars, the relevant literature was also analyzed further in this paper. Results show that the number of papers by Chinese scholars in WoS increased steadily since 2006 and reached a peak of 49 papers in 2010, which related to the Opportunities and Challenges-IFERA @China 2010 Family Firms Forum and First Chinese Entrepreneur Forum. There were 28 articles published at the forum. This was the first time that the International Family Enterprise Research Academy (IFERA) ${ }^{4}$ held the forum in a non-European country, so it reflected the importance of Chinese scholars in research on family firms and international attention. On the whole, apart from papers released at the forum, research on family firms in China showed an overall tendency of rising with fluctuations.

\section{Literature of Family Firms}

\subsection{Co-Occurrence of Keywords and Hot Research Topics}

A cluster table is a computational result when the keywords of a body of literature are entered in the CiteSpace software and the functionality of the Clusters menu is selected.

The Cluster ID is a number assigned after the clustering is performed, which is indicated as $0 \#, 1 \#, \ldots$ in the table. The bigger size the cluster is (i.e., a larger number of members in a cluster), the smaller the ID number will be. The S (silhouette) value is an indicator measuring the homogeneity of members in a cluster. If the $S$ value is close to 1 , it means the similarity of the cluster members.

\subsubsection{Co-Occurrence of Keywords of WoS}

Figure 2 shows a cluster analysis based on keyword co-occurrence, the results of which were trimmed to a selection of seven clusters, with larger cluster modules ${ }^{4}$ IFERA is the only academic organization in the world that specializes in the study of family firms. 


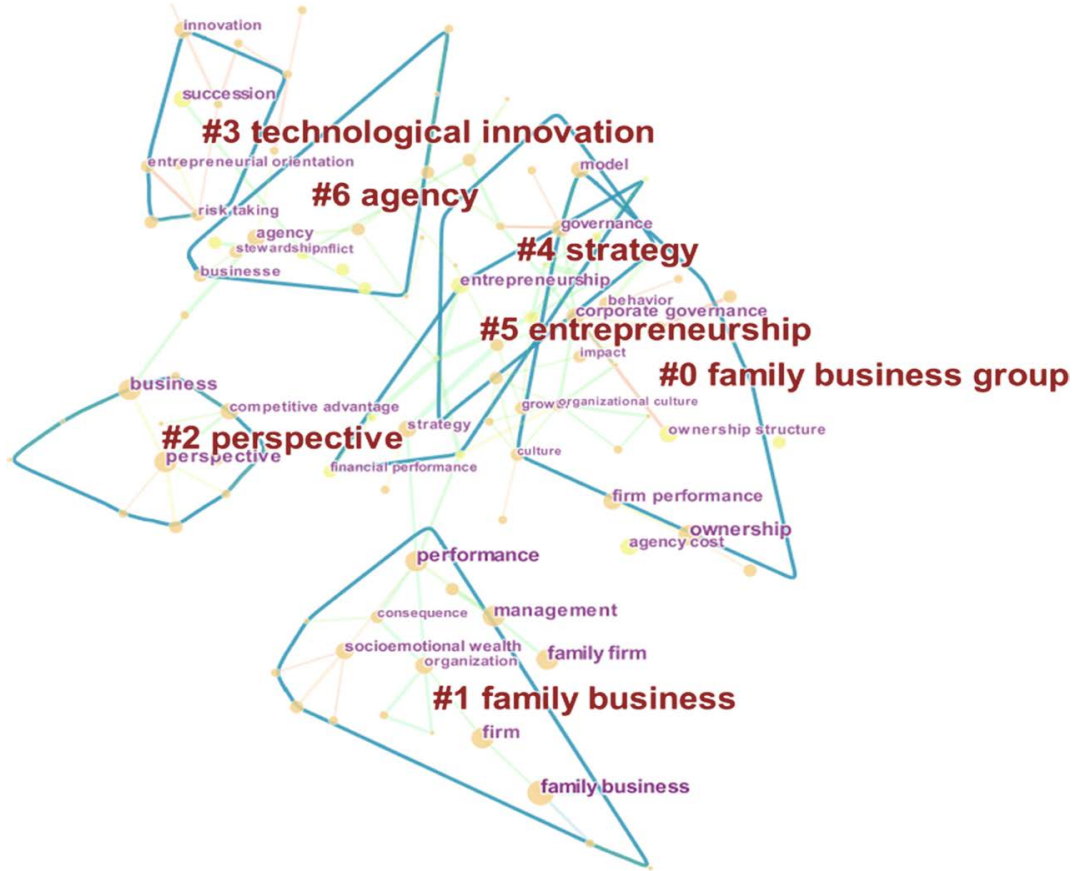

Figure 2. Clusters of keywords in WoS.

Table 1. Clustering of keywords of WoS.

\begin{tabular}{lllll}
\hline Type & No. & Name & S & Keywords \\
\hline 1 & 0 & Family firms group & 0.778 & $\begin{array}{l}\text { Family firms group; corporate governance; emerging } \\
\text { market; culture; ownership and control }\end{array}$ \\
2 & 2 & Perspective & 0.906 & $\begin{array}{l}\text { Perspective; stress; conservation; strategic } \\
\text { management; future challenge }\end{array}$ \\
3 & 3 & $\begin{array}{l}\text { Technological } \\
\text { innovation }\end{array}$ & 0.891 & $\begin{array}{l}\text { Technological innovation; risk taking; entrepreneurial } \\
\text { orientation; development investment; founder firm }\end{array}$ \\
4 & 4 & Strategy & 0.807 & $\begin{array}{l}\text { Strategy; diversification; misallocation; corporate } \\
\text { ownership; family management }\end{array}$ \\
& 5 & Entrepreneurship & 0.905 & $\begin{array}{l}\text { Entrepreneurship; industry; family firms success; } \\
\text { socioemotional wealth; owner; }\end{array}$ \\
5 & 6 & Agency & 0.842 & $\begin{array}{l}\text { Agency; stewardship theory; intragroup conflict; top } \\
\text { management team; organizational trust }\end{array}$ \\
\hline
\end{tabular}

representing hot research topics about family firms. The specific results are shown in Table 1. In terms of size, the seven clusters all cover at least 10 nodes, with $\mathrm{S}$ values ${ }^{5}$ larger than 0.778 , reflecting reasonable clustering and clear-cut themes. From these clustering results, hot research topics about family firms include governance of family firm groups, a definition of family firms, relevant research approaches, and family visions, as well as technological innovation, strategic decision-making, entrepreneurship, and family firm agencies. In combina-

${ }^{5}$ The $\mathrm{S}$ value evaluates clustering effects, indicating more reasonable sample clustering when closer to 1 . 
tion with these clustering results and intercluster relationships, we summarizes and discusses the following hot research topics about family firms in other countries:

Family firm groups and family firms. Cluster 0 and Cluster 1 are discussed together, mainly including subclusters such as corporate governance, control, and firm performance. Family firms in WoS have a long history. One characteristic that distinguishes family firms between western developed countries and China is the establishment of family councils. Family councils can lead family firm groups and family funds, specify the duties of family members, achieve a smooth succession of family firms, and maintain harmony within families [9]. This not only guarantees ownership and control by family members [10] [11] and continuity of family interests, but also enables family firms to meet the challenges of various risks and opportunities through diversified development.

Future prospect of family firms and challenges they will face. This cluster includes subclusters such as conservative attitudes about the future, strategic management, and future challenges for enterprises. The risk preferences of family owners play a decisive role in the future development and direction of enterprises, which is also one of the characteristics distinguishing family firms from non-family firms [12]. The strategic management and grasp of future opportunities will influence long-term development of family firms [13].

Innovation of family firms. This cluster contains the subclusters of technological innovation, risk-taking, and entrepreneurial orientation. In studies of firm innovation, different ownership structures of family firms affect their risk preferences and thus their research and development (R\&D) investments. However, there are different results of how family involvement impacts $R \& D$ of family firms. Some scholars believe that family firms prefer to pursue established strategies over long periods of time and providing permanent R\&D investments [14]. Other scholars posit that enterprises tend to make relatively conservative strategic decisions to avoid the loss of family interests, which can hinder investment in R \& D [15]. For scholars, it is worth further discussing the reasons for such contradictory findings.

The entrepreneurship and strategies of family firms. Cluster 4 and Cluster 5 are discussed together. These two clusters contain the subclusters of entrepreneurship, success, socioemotional wealth, and business diversification of family firms. Entrepreneurs lead the market economy, and entrepreneurship is the soul of entrepreneurs, and it play a prominent role in family firms, which often have an entrepreneurial base [16] [17]. The complementary strategic behavior and entrepreneurial activities of family firms can help them maximize wealth.

Strategic entrepreneurship also becomes a hot research topic in international academic circles. As an example, the Strategic Management Society of the United States launched a magazine, the Strategic Entrepreneurship Journal. To maximize inheritance, family firms depend on family entrepreneurship. Inheritors internalize their families' spirit through a series of strategic entrepreneurial 
actions, such as keeping up with the times, to guarantee their businesses' longterm success [18].

Agencies of family firms. Continuous development of family firms restricts their ability of relying solely on family members, an issue that can be solved by hiring professional managers, though this solution will cause agency conflict. Scholars have focused on how to settle the question of information asymmetry when family members and senior management teams have different goals [19].

\subsubsection{Co-Occurrence of Keywords of CSSCI}

Figure 3 shows the seven clusters representing the hot research topics on Chinese family firms. Table 2 shows that the seven clusters all exceed 10, with all $\mathrm{S}$

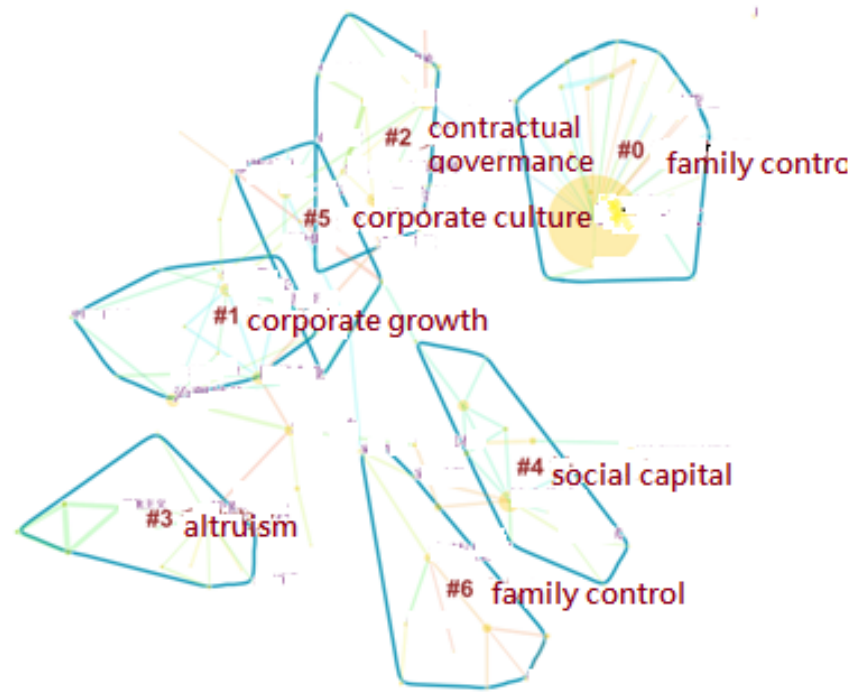

Figure 3. Clusters of keywords of CSSCI.

Table 2. Clustering of keywords of CSSCI.

\begin{tabular}{|c|c|c|c|c|}
\hline Type & No. & Name & S & Keywords \\
\hline \multirow[t]{2}{*}{1} & 0 & Family control & 0.992 & $\begin{array}{l}\text { Family control; external equity; earnings management; } \\
\text { altruism; family rationality }\end{array}$ \\
\hline & 6 & Family control & 0.875 & $\begin{array}{l}\text { Family control; succession intention; socioemotional } \\
\text { wealth; family governance; family ownership }\end{array}$ \\
\hline \multirow[t]{2}{*}{2} & 1 & $\begin{array}{l}\text { Corporate } \\
\text { growth }\end{array}$ & 0.84 & $\begin{array}{l}\text { Corporate growth; institutional innovation; principal-agent } \\
\text { relation; governance structure; firm performance }\end{array}$ \\
\hline & 5 & $\begin{array}{l}\text { Corporate } \\
\text { culture }\end{array}$ & 0.714 & $\begin{array}{l}\text { Corporate culture; institutional environment; property } \\
\text { rights system; incentive mechanism; social responsibility }\end{array}$ \\
\hline \multirow[t]{2}{*}{3} & 2 & $\begin{array}{l}\text { Contractual } \\
\text { governance }\end{array}$ & 0.837 & $\begin{array}{l}\text { Contractual governance; relational governance; professional } \\
\text { manager; agency theory; family employees }\end{array}$ \\
\hline & 3 & Altruism & 0.991 & $\begin{array}{l}\text { Altruism; family rationality; family interest; corporate } \\
\text { governance; intergenerational transition }\end{array}$ \\
\hline 4 & 4 & Social capital & 0.901 & $\begin{array}{l}\text { Social capital; private enterprise; enterprise governance } \\
\text { structure; governance model; control rights }\end{array}$ \\
\hline
\end{tabular}


values above 0.714. Based on clustering results and intercluster relationships, we integrated the seven clusters and discuss them in four areas.

Family control. Cluster 0 and Cluster 6 are considered family control. Even though the study of family firms is from different perspectives, the reason why the two clusters having same laber is that they both include "family control" in their keywords. In these two clusters, "family control" ranked first among subcluster names. Considering the mean year and size of the clusters, research on Chinese family firms focuses on family control, an initial characteristic of family firms that can persist for a long time [20] [21] [22]. Additional research on family control has prompted a shift of focus from antagonism between families and businesses to exploring how to settle conflicts between families and businesses (socioemotional wealth) and how to guarantee long-term development of businesses (willingness of succession).

Enterprise growth and enterprise culture. Cluster 1 and Cluster 5 address internal business governance. When family firms protect the interests of the family, business growth can be affected to a certain extent. As a result, many family firms are confused about the way to achieve a more harmonious agency relationship between family members and external members through system innovation, in order to realize smooth business growth [23] [24]. Construction of an enterprise culture is important to guarantee its long-term development. In this regard, Chinese family firms are quite different from non-family firms [25] [26], which need to focus on how to establish a successful enterprise system and incentive policies to recharacterize family characteristics for competitive advantage.

Contractual governance and altruism. Cluster 2 and Cluster 3 are concerned with the altruism of family firms, combining family interests at an initial stage of development to create competitive advantage with continuous business development. However, the pursuit of the whole family benefits may cause several agency problems [27]. Researchers have widely accepted that family altruism constitutes an important characteristic of family firms. A large number of studies have been conducted to examine the effect of altruism on these firms. These studies mainly focus on the relationship between altruism and agency. Altruism facilitates family employees to become co-owners of a firm. Co-ownership binds the interests of family firm owners and their family employees together [28], thereby reducing the cost of contractual governance [29]. Altruism enhances communication and collaboration among family members and reduces information asymmetry between the owners of family firms and family employees, which could increase the effectiveness of informal contractual governance [30].

To sum up, the effect of altruism on the principal-agent of family firms is neither purely positive nor negative, and the effect of the moral elements in this relationship cannot be underestimated. Family firms should thoroughly understand altruism and reduce the cost of contractual governance.

Social capital. Relationships are highly valued in Chinese society, and family firms in such a relationship-based society will inevitably have to weigh the law of demand against the law of human relations in the process of management and 
development [31] [32]. For family firms, family is the core of social capital, and Chinese family firms need to consider how to break through traditional family-oriented ideas to build more scientific governance structures within existing social networks to achieve transformational development.

\subsection{Burst Terms and Research Tendency}

In this field of research, scholars have focused on different issues at different times. CiteSpace detects current research trends attracting the attention of most scholars by using burst terms detection.

\subsubsection{Burst Terms and Research Frontier of WoS}

\section{1) The burst terms that have lasted the longest}

Figure 4 has shown that burst terms of WoS. Through detection of burst terms in WoS, we found that "gender" merged first (in 1988) and lasted the longest (until 2007). Scholars first discussed and analyzed the concept of "family" when they began to study family firms. Family firms largely developed from small businesses run by families, in which male and female members played different roles, thus forming different enterprise development patterns [33]. Because of different traditions and cultural backgrounds, the division of power and management of labor between male and female family members have attracted the long-term attention of scholars. In addition, succession in family firms is also a key point that distinguishes family firms from non-family firms. As the economic development collides with traditional culture, family controllers have caused problems of inheritance and choosing between male and female successors [34] [35]. Clearly, gender has influenced firms' internal mechanisms.

\section{2) The strongest burst terms}

The hot keyword "socioemotional wealth," which burst in 2014, appeared late but had the highest strength of 11.81. In their theory of socioemotional wealth, Gomezmejia et al. [36] pointed out that socioemotional wealth is an important element in the governance and strategy of family firms. In studying family firms,

\section{Top 9 Keywords with the Strongest Citation Bursts}

Keywords

Gender

Confict

\section{Altrusim}

Family business

Strategic management

Involvement

Entrepreneurial orientation

\section{Socioemotional wealth}

Development investment

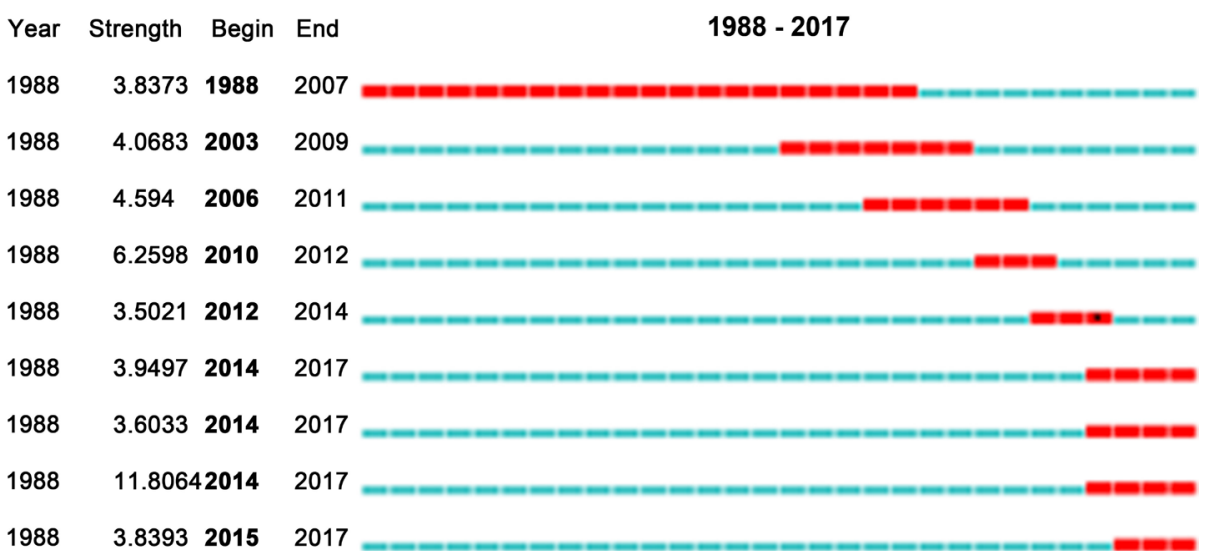

Figure 4. Burst terms of WoS. 
scholars have always disputed the nature of the conflict between family and corporate interests. The theory of socioemotional wealth provides a new perspective for the study of family firms, solving the long-standing problem that scholars interpret family interests without also considering corporate and economic interests. Since research on socioemotional wealth is in its initial stage, it remains just a qualitative concept at present [37]. Future research should specify the structural dimensions of this theory and improve its measurement methods from a quantitative perspective, to more clearly show the influence of socioemotional wealth on family firms.

\section{3) The burst terms that appeared last}

The hot keyword "development investment," which burst in 2015, is the last burst term to be considered. Some existing literatures focused on innovation and investment development of family firms, which enable them to maintain competitive advantage. Although the scale, financing, and technology of family firms can make progress difficult, many firms seem willing to undertake entrepreneurial development to gain competitive advantage [38].

From the analysis of these three burst terms of WoS as shown in Figure 4, we find that family firms have existed for a longer period of time in western developed countries than in China. Initially, scholars of WoS studied the structure and orientation of insiders. The introduction of professional managers has caused a degree of conflict with family members and has affected the management of enterprises, which attracted attentions of scholars. Additionally, the hot keywords "altruism" and "socioemotional wealth" indicate that the theoretical basis for family firms has shifted from altruism to socioemotional wealth. The theory of socioemotional wealth unravels contradictions between families and firms from a new perspective, providing theoretical support for a balance between family interests and corporate interests. On this basis, the research of enterprise investments provides a new direction for the long-term development of enterprises.

\subsubsection{Burst Terms of CSSCI}

\section{1) The burst terms lasting the longest}

Figure 5 has shown that burst terms of CSSCI. In studies of Chinese family firms, the hot keyword "intergenerational succession" lasted for the longest time after it burst in 2008 (it remains a burst term). Chinese family firms have only developed for a short time, and the founders of many family firms began to face the problem of succession in recent years. Despite such diverse factors as traditional culture, growth, industry features, and scale, "carrying on the parents' cause" is a major form of succession in many Chinese family firms. The historical family culture of China will make the family model a major choice for enterprises [39], but company founders may hesitate due to many problems involved in carrying on the parents' cause. This generates a "pan-family" succession model, expanding the range of successors to cover relatives, friends, and even professional managers [40]. The problems of power and the allocation of business interests in 
Top 10 Keywords with the Strongest Citation Bursts

\begin{tabular}{|c|c|c|c|c|c|c|}
\hline Keywords & Year & Strength & Begin & End & $1998-2015$ & \\
\hline business management & 1998 & 4.5306 & 1998 & 2003 & & \\
\hline intitutional change & 1998 & 2.985 & 2002 & 2006 & I & \\
\hline listed company & 1998 & 3.0157 & 2003 & 2006 & 1 & h \\
\hline modern enterprise system & 1998 & 5.0561 & 2003 & 2006 & -1 & $1 \mathrm{~s}$ \\
\hline governance structure & 1998 & 3.0428 & 2003 & 2009 & $\mathbf{I}$ & \\
\hline intergenerational transition & 1998 & 3.4471 & 2008 & 2015 & 1 & \\
\hline governance model & 1998 & 2.9586 & 2009 & 2010 & $\mathbf{I}$ & \\
\hline agency cost & 1998 & 3.4225 & 2012 & 2015 & 1 & Phase 2 \\
\hline family control & 1998 & 6.0342 & 2013 & 2015 & $\mathbf{I}$ & \\
\hline family involvement & 1998 & 5.3579 & 2013 & 2015 & 1 & \\
\hline
\end{tabular}

Figure 5. Burst terms of CSSCI.

"pan-families" are worth further discussion.

2) The strongest burst terms

The hot keyword "family control," which is the strongest burst term, appeared late, in 2013. Scholars in China have not achieved consensus on the definition of family firms, but all commonly recognize definitions involving family control and family ownership. Ownership and control generally are highly centralized in Chinese family firms, which have a more prominent interest conflict with minor shareholders [41] [42]. How to balance family interests and corporate interests to guarantee long-term business development is an urgent problem that Chinese family firms have to solve now.

3) The burst terms that appeared last

The hot keywords "family involvement" and "family control," which began in 2013, are the latest burst terms. "Family control" is not only the last, but also the strongest burst term. It clearly shows the respect for authority in Chinese family firms, under the influence of the unique Chinese family culture. However, such control can also cause prominent problems in enterprise $R \& D$, performance, and succession [43] [44]. In addition, the characteristic of differential sequence pattern [45] in Chinese social relationships leads to the focus of makes Chinese scholars on family authority.

A burst analysis of three Chinese keywords in Figure 5 indicates that 2008 was a dividing year for research on family firms in China. Earlier, the major research focused on enterprises, including internal governance and enterprise transitions. In other words, family firms were just a type of organization, not highlighting the family characteristics. After the financial crisis in 2008, scholars began to shift their attention to the significant role of family. Because Chinese family firms started late, most of them have just recently entered the stage of succession. Scholars, following this trend, are becoming interested in intergenerational succession and the agency of professional managers. 


\section{Conclusions}

In this study, we present a comparative analysis of family firms using CiteSpace based on data extracted from WoS and CSSCI. The results manifest that many scholars of WoS have conducted extensive research on the governance structure, inheritance, and performance assessment of family firms. From the research trend of WoS, we can see that the focus of family firms has been a deep analysis of how family characteristics could better influence the enterprise strategy and entrepreneurship process. When explaining the split problems between family interests and firm interests, it also transforms from the previous economic perspective into a brand-new perspective of socioemotional wealth theory.

The studies in WoS are relatively mature. There are many places to learn and reference for China. However, the studies of Chinese family firms should not be imitated completely, whereas the studies of family firms between China and other countries have similarities and differences, which will significantly facilitate the sustainable study of Chinese family firms. In terms of similarities, as in other countries, Chinese researchers focus on the study of family firms' strategies, including family involvement, corporate governance, and decision-making. However, as can be seen from the comparison along the temporal trend, there are striking problems about the dilemma between family control and financing needs, and the inheritance of the next generation from the family founder. So the studies of Chinese family firms are interested in financing and the willingness to inherit a family firm.

An important factor that Chinese family firms concern on is the issues of financial constraint and inheritance. Compared to family businesses in western developed countries, Chinese family businesses are sensitive to the institutional environment. Family business leaders are sensitive to changes of the institutional environment, and they are aware of whether the family can continue to control the enterprise and maintain the family's socioemotional wealth under the current institutional environment. The development of Chinese family firms closely relates to the evolution of Chinese politics. The world has witnessed China's economic growth rate, international market expansion, and national strategy of vigorously developing strategic emerging industries and constructing resourcesaving enterprises and society, which means both opportunities and challenges for family firms are growing. Embedded in such macro background, it is necessary for scholars to further study the long-term development, entrepreneurial activities, eco-environmental efficiency, and international competition of family firms. Chinese scholars should build a theoretical system and research method that are suitable for family business studies in combination with the unique system of China, and then enrich the knowledge accumulation of family firm research in the world.

Through analyzing the knowledge map of family firms, we aim for providing certain theoretical basis for a sustainable study of family firms. We find that research on family firms presents a growing trend. As the increased of number and 
status of family firms in China, the research on family firms in China cannot be neglected. However, this paper simply compares and analyzes the hot topics and tendencies in family firm research. In future studies, we could classify family firms from different dimensions of definitions and growth stages, and then examine the hot topics and tendencies in the field of research. Through this dynamic view, we could grasp the developments of various subjects of family firms.

\section{Conflicts of Interest}

The authors declare no conflicts of interest regarding the publication of this paper.

\section{References}

[1] Liao, H., Tang, M., Luo, L., et al. (2018) A Bibliometric Analysis and Visualization of Medical Big Data Research. Sustainability, 10, 166. https://doi.org/10.3390/su10010166

[2] Merigó, J.M., Cancino, C.A., Coronado, F. and Urbano, D. (2016) Academic Research in Innovation: A Country Analysis. Scientometrics, 108, 559-593. https://doi.org/10.1007/s11192-016-1984-4

[3] Železnik, D., Blažun Vošner, H. and Kokol, P. (2017) A Bibliometric Analysis of the Journal of Advanced Nursing, 1976-2015. Journal of Advanced Nursing, 73, 2407-2419. https://doi.org/10.1111/jan.13296

[4] Niu, B., Loáicig, H.A., Wang, Z., Zhan, F.B. and Hong, S. (2014) Twenty Years of Global Groundwater Research: A Science Citation Index Expanded-Based Bibliometric Survey (1993-2012). Journal of Hydrology, 519, 966-975.

https://doi.org/10.1016/j.jhydrol.2014.07.064

[5] Vergidis, P.I., Karavasiou, A.I., Paraschakis, K., Bliziotis, I.A. and Falagas, M.E. (2005) Bibliometric Analysis of Global Trends for Research Productivity in Microbiology. European Journal of Clinical Microbiology \& Infectious Diseases, 24, 342-346. https://doi.org/10.1007/s10096-005-1306-x

[6] Chen, C. (2004) Searching for Intellectual Turning Points: Progressive Knowledge Domain Visualization. Proceedings of the National Academy of Sciences of the United States of America, 101, 5303-5310. https://doi.org/10.1073/pnas.0307513100

[7] Chen, C. (2006) CiteSpace II: Detecting and Visualizing Emerging Trends and Transient Patterns in Scientific Literature. Journal of the American Society for Information Science and Technology, 57, 359-377. https://doi.org/10.1002/asi.20317

[8] Li, X.-J., Ma, E. and Qu, H.-L. (2017) Knowledge Mapping of Hospitality Research-A Visual Analysis Using CiteSpace. International Journal of Hospitality Management, 60, 77-93.

[9] Scherer, F.M. and Huh, K. (1992) Top Managers Education and R \& D Investment. Research Policy, 21, 507-511. https://doi.org/10.1016/0048-7333(92)90007-Q

[10] Kellermanns, F.W. and Eddleston, K.A. (2007) A Family Perspective on when Conflict Benefits Family Firm Performance. Journal of Business Research, 60, 1048-1057. https://doi.org/10.1016/j.jbusres.2006.12.018

[11] Eddleston, K.A., Otondo R.F. and Kellermanns, F.W. (2008) Conflict, Participative Decision-Making, and Generational Ownership Dispersion: A Multilevel Analysis. Journal of Small Business Management, 46, 456-484. https://doi.org/10.1111/j.1540-627X.2008.00252.x 
[12] Minola, T., Brumana, M., Campopiano, G., Garrett, R.P. and Cassia, L. (2016) Corporate Venturing In Family Business: A Developmental Approach of the Enterprising Family. Strategic Entrepreneurship Journal, 10, 395-412. https://doi.org/10.1002/sej.1236

[13] Revilla, A.J., Pérez-Luño, A. and Nieto, M.J. (2016) Does Family Involvement in Management Reduce the Risk of Business Failure? The Moderating Role of Entrepreneurial Orientation. Family Business Review, 29, 365-379. https://doi.org/10.1177/0894486516671075

[14] Lee, P.M. and O’Neill, H.M. (2003) Ownership Structures and R \& D Investments of U.S. and Japanese Firms: Agency and Stewardship Perspectives. Academy of Management Journal, 46, 212-225. https://doi.org/10.2307/30040615

[15] Anderson, R.C. Mansi, S.A. and Reeb, D.M. (2003) Founding Family Ownership and the Agency Cost of Debt. Journal of Financial Economics, 68, 263-285. https://doi.org/10.1016/S0304-405X(03)00067-9

[16] Zellweger, T.M. and Nason, R.S. (2008) A Stakeholder Perspective on Family Firm Performance. Family Business Review, 21, 203-216. https://doi.org/10.1177/08944865080210030103

[17] Gedajlovic, E., Carney, M., Chrisman, J.J. and Kellermanns, F.W. (2012) The Adolescence of Family Firm Research: Taking Stock and Planning for the Future. Journal of Management, 38, 1010-1037. https://doi.org/10.1177/0149206311429990

[18] Li, X.-C., He, X. and Chen, W.-T. (2008) Starting an Undertaking in Terms of Strategy, and the Succession of Entrepreneurialism of Clannish Firms: A Case Study Based on Lee Kum Kee-A Century-Old Shop. Management World, 20, 127-140.

[19] Schulze, W.S., Lubatkin, M.H. and Dino, R.N. (2002) Altruism, Agency, and the Competitiveness of Family Firms. Managerial and Decision Economics, 23, 247-259. https://doi.org/10.1002/mde.1064

[20] Chen, D., Yang, J. and Dong, Z.-Y. (2013) Family Control, Professional Management and Corporate Governance Efficiency: Evidence from CEO Turnover in Chinese Listed Companies. Nankai Business Review.

[21] Chen, X., Yin, Z. and Wu, X. (2007) Pyramid Structure, Family Control and Enterprises' Value: An Empirical Research Based on Shanghai and Shenzhen Stock Markets. Nankai Business Review, 10, 47-54.

[22] He, X.-G., Lian, Y.-L., Li, J. and Mei, L. (2010) Kinship's Effects on Family Firms' Growth: An Empirical Study in China. China Industrial Economics.

[23] Wang, M. and Chen L. (2010) Private Listed Companies in China: Family Governance and Firm Value. Nankai Business Review, 13, 61-70.

[24] Li, N. and Wang, X. (2014) Family Governance and Firm Performance based on the Institutional Perspective: Comparative Evidence from Chinese and Germany Listed Family Firms. South China Journal of Economics.

[25] Hu, X.-Y., Wu, Y.-P. and Finance, S.O. (2016) Study on Transgenerational Transfer of Political Capital of Chinese Family Firm-An Empirical Analysis Based on Entrepreneurs' Membership of PC or CPPCC. China Industrial Economics.

[26] Jing, X.-I. (2007) Organizational Identification and Family Firms' Growth in China. Economic Management.

[27] Chen, J. (2011) Altruism, Agency Costs and Family Business Growth. Management Review.

[28] Stark, O. and Falk, I. (1998) Transfers, Empathy Formation, and Reverse Transfers. The American Economic Review, 88, 271-276. 
[29] Schulze, W.S., Lubatkin, M.H. and Dino, R.N. (2003) Toward a Theory of Agency and Altruism in Family Firms. Journal of Business Venturing, 18, 473-490. https://doi.org/10.1016/S0883-9026(03)00054-5

[30] Daily, C.M. and Dollinger, M.J. (2010) An Empirical Examination of Ownership Structure in Family and Professionally Managed Firms. Family Business Review, 5, 117-136. https://doi.org/10.1111/j.1741-6248.1992.00117.x

[31] Chu, X. (2003) Social Relationship Capital and Chinese Familial Enterprise's Entrepreneurship and Development. Nankai Business Review.

[32] Chen, Q.-Q. and Yin, Y.-H. (2014) Private Enterprises, Institutional Environment and Social Capital: Evidence from Listed Family Firms. Journal of Finance \& Economics, 40, 71-79.

[33] Peake, W.O., Cooper, D., Fitzgerald, M.A., Fitzgerald, M.A. and Muske, G. (2017) Family Business Participation in Community Social Responsibility: The Moderating Effect of Gender. Journal of Business Ethics, 142, 325-343. https://doi.org/10.1007/s10551-015-2716-Z

[34] Rutherford, M.W., Muse, L.A. and Oswald, S.L. (2006) A New Perspective on the Developmental Model for Family Business. Family Business Review, 19, 317-333. https://doi.org/10.1111/j.1741-6248.2006.00079.x

[35] Bennedsen, M., Nielsen, K.M., Perez-Gonzalez, F. and Wolfenzon, D. (2007) Inside the Family Firm: The Role of Families in Succession Decisions and Performance. The Quarterly Journal of Economics, 122, 647-691. https://doi.org/10.1162/qjec.122.2.647

[36] Gomez-Mejia, L.R., Cruz, C., Berrone, P. and De Castro, J. (2011) The Bind that Yies: Socioemotional Wealth Preservation in Family Firms. Academy of Management Annals, 5, 653-707. https://doi.org/10.5465/19416520.2011.593320

[37] Cennamo, C., Berrone, P., Cruz, C. and Gomez-Mejia, L.R. (2012) Socioemotional Wealth and Proactive Stakeholder Engagement: Why Family-Controlled Firms Care More about Their Stakeholders. Entrepreneurship Theory \& Practice, 36, 1153-1173. https://doi.org/10.1111/j.1540-6520.2012.00543.x

[38] Broekaert, W., Andries, P. and Debackere, K. (2016) Innovation Processes in Family Firms: The Relevance of Organizational Flexibility. Small Business Economics, 47, 771-785. https://doi.org/10.1007/s11187-016-9760-7

[39] Chen, L. and Y, L.-F. (2003) Hereditary Succession: The Inheritable Management and Creation in Clannish Enterprises. Management World.

[40] Hu, G.-D. (2014) Research on the Family Metaphor of Chinese Local Organization and Its Network Governance Mechanism-Based on the Perspective of Enlarged Familism. China Industrial Economics.

[41] Gongmen, C. (2011) On the Family Control, Institutional Environment and Corporate Valuation. Journal of Financial Research.

[42] Chen, Z.-J. and Min, Y.-J. (2015) The Impact of Family Control on Corporate Social Responsibility: From the Perspective of Socioemotional-Wealth Theory. Economic Management Journal.

[43] Yan, R.-S. and Ye, Y.-L. (2014) Family Ownership, Family Involvement in Management and the Level of Enterprise R \& D Investment: From the Perspective of Socioemotional Wealth. Economic Management Journal.

[44] Liang, Q., Liu, J., Zhou, L. and Xu, E. (2013) How Does Next Generation Involvement Increase Firm Value Evidence from Listed Family Firms in China. South China Journal of Economics. 
[45] Wang, L. (2015) The Influence of Differential Leadership on Employee and Team Creativity in Chinese Family Businesses: A Multilevel and Longitudinal Study. Advances in Psychological Science, 23, 1688-1700.

https://doi.org/10.3724/SP.J.1042.2015.01688 